\title{
Autosomal dominant cerebellar ataxia with retinal degeneration (ADCA II): clinical and neuropathological findings in two pedigrees and genetic linkage to $3 \mathrm{p} 12-\mathrm{p} 21.1$
}

G J Jöbsis, J W Weber, P G Barth, H Keizers, F Baas, M J van Schooneveld, $\mathrm{J} J$ van Hilten, D Troost, H H Geesink, P A Bolhuis

$M \mathrm{~J}$ van Schooneveld

Department of

Neurology of the

Academic Hospital,

University of Leiden,

The Netherlands

$J J$ van Hilten

Correspondence to:

Dr G J Jobsis, Department of

Neurology (H2-214),

Academic Medical Center,

PO Box 22700, 1100 DE

Amsterdam, The

Netherlands.

Received 26 August 1996

and in final revised form

8 November 1996

Accepted 25 November 1996

$(\mathcal{F}$ Neurol Neurosurg Psychiatry 1997;62:367-371)

Keywords: autosomal dominant cerebellar ataxia; retinal degeneration; anticipation; genetic linkage

The classification of autosomal dominant cerebellar ataxias (ADCAs) proposed by Harding distinguishes cerebellar ataxia with pigmentary retinal degeneration as a distinct category-that is, ADCA type II. ${ }^{12}$ Associated features that are variably present include oph-

\begin{abstract}
Department of Neurology

G J Jöbsis

JW Weber

P G Barth

H Keizers

F Baas

H H Geesink

P A Bolhuis

Department of

Pediatrics

J W Weber

P G Barth

H H Geesink

Department of Pathology

(Neuropathology),

Academic Medical

Center, University of

Amsterdam, The

Netherlands

P G Barth

D Troost

Netherlands

Ophthalmic Research

Institute, Amsterdam,

The Netherlands

Abstract

Objectives-To investigate relations between clinical and neuropathological features and age of onset, presence of anticipation, and genetic linkage in autosomal dominant cerebellar ataxia type II (ADCA II).

Methods-The natural history of ADCA II was studied on the basis of clinical and neuropathological findings in two pedigrees and genetic linkage studies were carried out with polymorphic DNA markers in the largest, four generation, pedigree.

Results-Ataxia was constant in all age groups. Retinal degeneration with early extinction of the electroretinogram constituted an important component in juvenile and early adult ( $<25$ years) onset but was variable in late adult presentation. Neuromuscular involvement due to spinal anterior horn disease was an important contributing factor to illness in juvenile cases. Postmortem findings in four patients confirm the general neurodegenerative nature of the disease, which includes prominent spinal anterior horn involvement and widespread involvement of grey and white matter. Genetic linkage was found with markers to chromosome 3p12-p21.1 (maximum pairwise lod score 4.42 at D3S1285).

Conclusions-The sequence of clinical involvement seems related to age at onset. Retinal degeneration is variable in late onset patients and neuromuscular features are important in patients with early onset. Strong anticipation was found in subsequent generations. Linkage of ADCA II to chromosome 3p12-p21.1 is confirmed.
\end{abstract} thalmoplegia, pyramidal or extrapyramidal signs, and sensory loss. Anticipation is commonly found.

The genetic loci implicated in ADCAs have been labelled and numbered as spinocerebellar ataxia (SCA) loci. For ADCA I, which differs from ADCA II mainly by the lack of pigmentary retinal degeneration, four loci have been identified (SCA1-4) with evidence for an additional, as yet unidentified (SCA6) locus. ${ }^{34}$ SCA5 is the genetic locus found in a large ADCA III pedigree. ${ }^{5}$ The molecular defect of SCA1 and SCA 3 consists of an expanded trinucleotide repeat; the mutations of the other SCA loci have yet to be characterised. Reflecting the distinguishing feature of pigmentary macular degeneration, ADCA II does not link to any of the ADCA I loci. ${ }^{67}$ Recently, ADCA II has been mapped to chromosome 3p in nine kindred without evidence for genetic heterogeneity, this locus has been named SCA7..$^{8-10}$

We studied 16 patients from two pedigrees fulfilling the ADCA II criteria ${ }^{2}$ : autosomal dominant inheritance of a progressive CNS disorder with predominantly cerebellar ataxia in combination with progressive visual failure due to pigmentary retinopathy. After excluding the SCA1-5 loci, a genome wide linkage analysis was undertaken in one pedigree. During this investigation, the SCA7 locus was reported $^{8-10}$ and we confirm linkage to this locus. Neuromuscular involvement leading to clinically evident spinal muscular atrophy is prominent in some members of both families. This feature seems to be accentuated in early onset cases. Neuropathological findings, similar in all cases, were likewise more prominent in cases with juvenile onset.

\section{Materials and methods}

Over the past 15 years members of the two families were examined by several neurologists and ophthalmologists. Figure 1 shows the families. Family 1 is part of a larger pedigree, of which ophthalmological findings have been previously reported. ${ }^{11}$ Family 2 has not been reported before. Patients were seen by at least one of the authors, with the exception of patient 2-I, 1 who was included on the basis of available medical records. Pathological anatomical data were available from two patients in each pedigree (1-II,5, 1-IV,2, 2II,3, 2-III,2). Muscle biopsies were performed in two patients. Muscle was studied at 


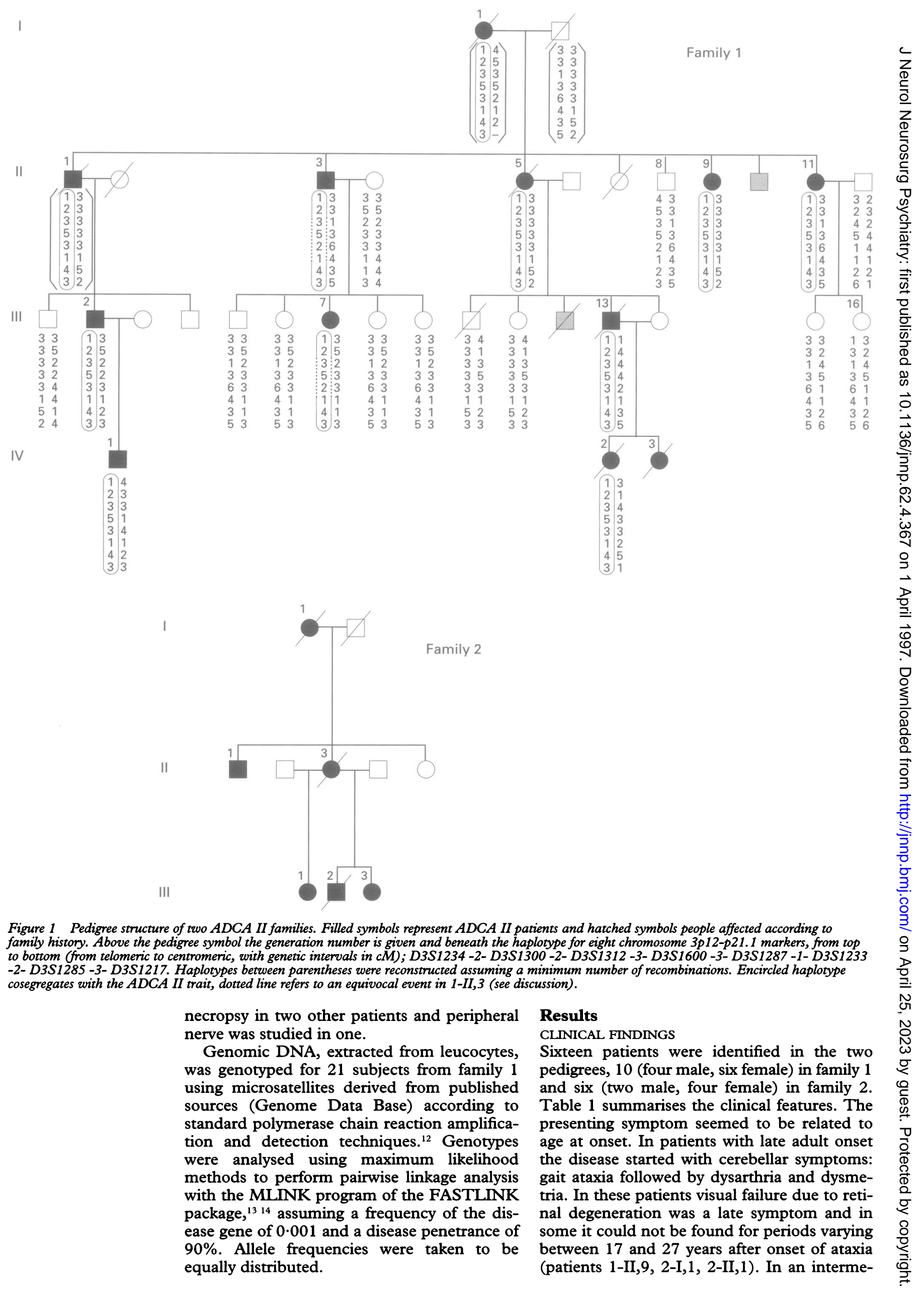


Table 1 Clinical features

\begin{tabular}{|c|c|c|c|c|c|c|c|c|c|c|c|}
\hline Patient & Sex & $\begin{array}{l}\text { Age at } \\
\text { onset }(y)\end{array}$ & Age (y) & $\begin{array}{l}\text { Cerebellar } \\
\text { symptoms }\end{array}$ & $\begin{array}{l}\text { Visual } \\
\text { failure }\end{array}$ & $\begin{array}{l}\text { Retinal } \\
\text { degeneration }\end{array}$ & $\begin{array}{l}\text { External } \\
\text { ophthal- } \\
\text { moplegia }\end{array}$ & Ptosis & $\begin{array}{l}\text { Pyramidal } \\
\text { tract signs }\end{array}$ & $\begin{array}{l}\text { PNS } \\
\text { clinically } \\
\text { involved }\end{array}$ & $\begin{array}{l}\text { Age when } \\
\text { wheelchair } \\
\text { bound }\end{array}$ \\
\hline $1-I I, 3$ & $\mathbf{M}$ & 45 & 84 & + & + & & + & & + & - & 70 \\
\hline 1-II,5 & $\mathrm{F}$ & 45 & $76^{\star}$ & + & + & + & + & - & + & - & 55 \\
\hline $1-\mathrm{II}, 9$ & $\mathrm{~F}$ & 50 & 75 & + & - & - & - & - & + & - & - \\
\hline 1-II,1 1 & $\mathrm{~F}$ & & 71 & + & + & - & - & - & + & - & - \\
\hline 1-III,2 & $M$ & 34 & 48 & + & + & + & + & - & + & - & - \\
\hline 1-III,7 & $\mathrm{F}$ & 31 & 40 & + & + & - & + & - & + & - & - \\
\hline 1-III, 13 & $M$ & 30 & $45^{\star}$ & + & + & + & + & & & & \\
\hline $1-\mathrm{IV}, 1$ & $M$ & 1.5 & 23 & + & $+t$ & + & + & - & + & - & - \\
\hline $1-I V, 2$ & $\mathrm{~F}$ & 7 & $19^{\star}$ & + & $+t$ & + & + & + & + & + & 15 \\
\hline $1-I V, 3$ & $\mathrm{~F}$ & $0 \cdot 25$ & $1^{\star}$ & + & + & + & & & & & \\
\hline $2-I, 1$ & $\mathrm{~F}$ & 40 & $67^{\star}$ & + & - & - & - & - & + & & - \\
\hline $2-I I, 1$ & $M$ & 40 & 57 & + & - & - & - & - & + & - & 50 \\
\hline $2-\mathrm{II}, 3$ & $\mathrm{~F}$ & 31 & $51^{\star}$ & + & + & + & + & + & + & + & 43 \\
\hline 2 -III, 1 & $\mathrm{~F}$ & 20 & 33 & + & $+t$ & + & + & - & + & - & 32 \\
\hline 2-III,2 & $M$ & 7 & $14^{\star}$ & + & $+t$ & + & + & + & + & + & 14 \\
\hline 2 -III, 3 & $\mathrm{~F}$ & 19 & 25 & + & $+t$ & + & + & - & + & - & - \\
\hline
\end{tabular}

*Age at death; otherwise recorded age is at 1 January 1995.

†Presenting symptom; if a space is left blank, no reliable information was available.

$+=$ sign present; $-=$ sign absent.

Figure 2 Fundoscopic findings in the youngest patient examined (2III,2). Left eyeground shows atrophic lesion in macular area and atrophy of the optic nerve head. Note the peripheral extension of circumscript atrophic lesions. diate group with adult onset disease, manifest retinopathy was preceded by ataxia (patients 1-II,5; 1-II,11; 1-III,2; 1-III,7; 1-III,13). In the youngest generation visual failure preceded ataxia (patients 1-IV,1; 1-IV,2; 2-III,1; 2-III,2; 2-III,3). Funduscopy showed a finely granular pigmentation in the macular area and slight pallor of the optic disc. In later stages the retina showed brownish pigment mottling and pale optic discs. In one patient with juvenile onset disease and rapidly progressive course, multiple atrophic round spots were seen both in the centre and in the periphery of the eyegrounds (fig 2). An extinguished electroretinogram (ERG) was found in four out of five cases, the single exception being a patient with late adult onset without clinical symptoms of eye involvement (patient 1-II,9). In patient 2-III,3 only mild optic nerve pallor with myopic fundi was seen, whereas the ERG showed severely reduced responses. Pyramidal tract signs, the third complex of symptoms, consisted of hyperreflexia with extensor plantar responses, and variable hypertonicity of limb musculature.

External ophthalmoplegia, possibly due to neuromuscular involvement, was present in 11

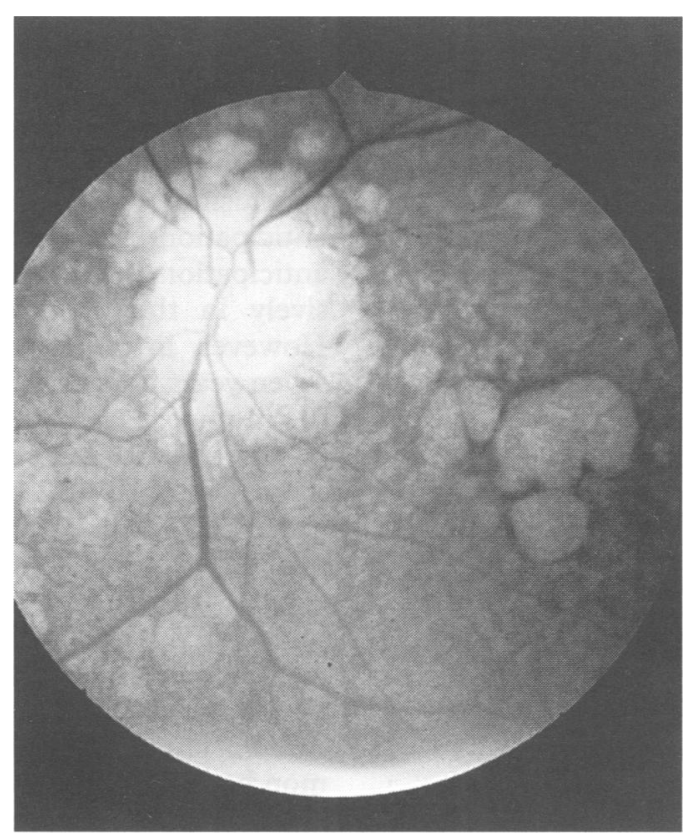

patients, accompanied by ptosis in a minority. More general involvement of the neuromuscular system was seen in some younger patients. This included facial palsy with prominent Bell's sign, swallowing difficulty, and lingual atrophy, together with weakness and wasting of extremity musculature in patients $1-\mathrm{IV}, 2$ and 2-III,2. Patient 2-III,2, the youngest, investigated at the age of 14 years, also had generalised myoclonus as part of terminal disease. In the absence of extrapyramidal symptoms or EEG signs of epilepsy it was suggestive of spinal myoclonus. No overt signs of dementia were seen in any patient. Even patients who were terminally ill remained alert and responsive to their environment.

Imaging studies (cerebral CT or MRI) disclosed cerebellar and brainstem atrophy to varying degrees but also signs of cerebral hemispheral atrophy (fig 3). Clinical neurophysiological investigation showed non-specific EEG alterations in advanced disease. Brainstem acoustic evoked potentials showed prolonged $\mathrm{I}-\mathrm{V}$ latencies. In later stages only peak I could be elicited. ERG potentials were of low voltage and absent in advanced disease stages. There were normal motor and sensory conduction velocities, EMG sometimes showed polyphasic action potentials.

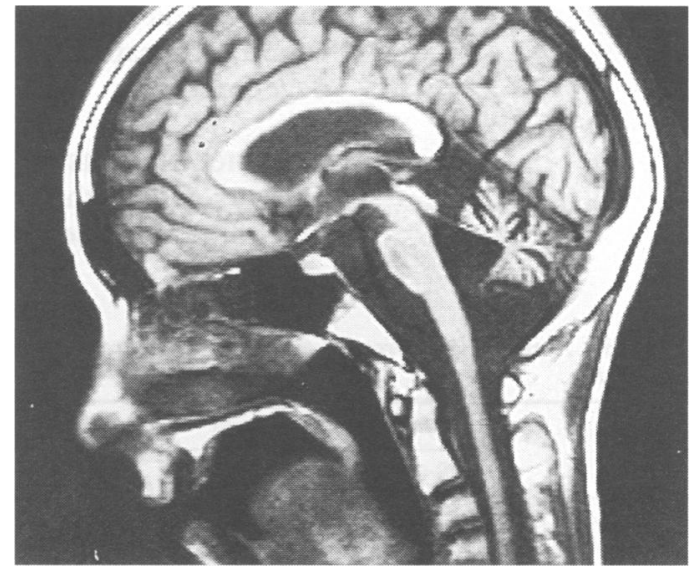

Figure 3 MRI findings in patient 1-IV,2, with onset of symptoms at age 7 years. MRI at age 17 years. Sagittal T 1 weighted image shows vermal cerebellar atrophy, attenuation of the ventral pons, and some cerebral (sub) cortical atrophy. 


\begin{tabular}{|c|c|c|c|c|}
\hline & \multicolumn{4}{|l|}{ Patient } \\
\hline & $1-I I, 5$ & $1-I V, 2$ & $2-I I, 3$ & $2-I I I, 2$ \\
\hline $\begin{array}{l}\text { Sex } \\
\text { Age at death (y) } \\
\text { Brain weight (g) } \\
\text { Macroscopic (sub)cortical atrophy } \\
\text { Ventricular widening } \\
\text { Pancerebellar atrophy } \\
\text { Atrophy ventral pons } \\
\text { Purkinje cells } \\
\text { Internal granular cells } \\
\text { Cerebellar white matter } \\
\text { Spinal motor neurons } \\
\text { Spinal long tract involvement: posterior columns, } \\
\text { pyramidal and spinocerebellar tracts } \\
\text { Inferior olivary neurons } \\
\text { Olivocerebellar tract } \\
\text { Central tegmental tract } \\
\text { Cerebral white matter } \\
\text { Cerebral cortex, loss of neurons in all layers } \\
\text { Skeletal muscle (m quadriceps femoris) }\end{array}$ & $\begin{array}{l}\text { F } \\
76 \\
1240(\mathrm{~N}) \\
+ \\
+ \\
- \\
+ \\
++ \\
- \\
- \\
++ \\
+ \\
+ \\
++ \\
+ \\
- \\
- \\
\text { (necropsy) } \\
\text { Normal except } \\
\text { type 2 atrophy }\end{array}$ & $\begin{array}{l}\text { F } \\
19 \\
1010(\downarrow) \\
+ \\
+ \\
+ \\
+ \\
+++ \\
++ \\
+++ \\
++ \\
+ \\
+++ \\
+++ \\
++ \\
++ \\
++ \\
\text { (biopsy) } \\
\text { Extensive type } \\
\text { grouping and } \\
\text { angulate fibres }\end{array}$ & $\begin{array}{l}\text { F } \\
51 \\
960(\downarrow) \\
+ \\
+ \\
+ \\
+ \\
+++ \\
\text { vermis only } \\
\text { vermis only } \\
++ \\
\\
+ \\
+++ \\
+++ \\
++ \\
++ \\
++ \\
++ \\
\text { (necropsy) } \\
\text { Extensive type } \\
\text { grouping }\end{array}$ & $\begin{array}{l}\text { M } \\
14 \\
975(\downarrow) \\
+ \\
+ \\
+ \\
+ \\
++++ \\
++ \\
+++ \\
++ \\
+ \\
+ \\
++++ \\
+++ \\
++ \\
++ \\
++ \\
\text { (biopsy) } \\
\text { Extensive type } \\
\text { grouping and } \\
\text { angulate fibres }\end{array}$ \\
\hline
\end{tabular}

$-=$ Not affected, $+=$ mildly affected, $++=$ moderately affected, $+++=$ subtotal loss of structure, $++++=$ total loss of structure.

NEUROPATHOLOGICAL EXAMINATIONS

Full routine necropsies including brain and spinal cord were available from four patients, two from each family. Table 2 summarises the findings. Visible atrophy of the cerebral hemispheres, including sulcal and ventricular widening, and ventral pontine atrophy were present in all four patients, and pancerebellar atrophy in three. Microscopical findings consisted of Purkinje cell loss, loss of spinal anterior horn cells-predominantly in the medial group-and loss of myelinated fibres, especially in the posterior columns but also involving the spinocerebellar and pyramidal tracts. There was loss of olivary neurons with reactive gliosis. The macroscopically visible atrophy of the cerebral cortex was associated with variable loss of neurons, ghost cells, gliosis, and microglial proliferation in all layers. White matter loss in the cerebral white matter was patchy, and present both in the central white matter and in the gyral cores. Although findings were similar in all cases, there were striking differences in expression; patient I-II,5 with late adult onset being the least affected, and 2III,2 with juvenile onset the most severely affected. Three of four muscle samples showed clear signs of chronic and acute denervation, indicative of an ongoing process of degeneration.

GENETIC ANALYSIS

After excluding the SCA1-5 loci for family 1 , a genome wide search was undertaken using

Table 3 Pairwise lod scores for ADCA II and chromosome 3p12-p21.1 markers for family 1

\begin{tabular}{llllll}
\hline \multirow{7}{*}{ Marker } & \multicolumn{5}{l}{ Recombination fractions } \\
\cline { 2 - 6 } & 0.00 & 0.01 & 0.05 & 0.10 & 0.20 \\
\hline D3S1234 & 3.61 & 3.57 & 3.39 & 3.10 & 2.41 \\
D3S1300 & 4.38 & 4.30 & 3.99 & 3.59 & 2.72 \\
D3S1312 & 2.03 & 1.99 & 1.85 & 1.65 & 1.33 \\
D3S1600 & 3.27 & 3.23 & 3.02 & 2.74 & 2.09 \\
D3S1287 & $-\infty$ & 1.15 & 1.64 & 1.67 & 1.37 \\
D3S1233 & 1.13 & 1.10 & 1.01 & 0.88 & 0.60 \\
D3S1285 & 4.42 & 4.35 & 4.04 & 3.64 & 2.78 \\
D3S1217 & 2.56 & 2.52 & 2.36 & 2.13 & 1.60 \\
\hline
\end{tabular}

microsatellite markers without detecting linkage (data not shown). After reports of linkage to chromosome $3 \mathrm{p} 12-\mathrm{p} 21.1^{8-10}$ we investigated the markers shown in table 3. Significant two point lod scores were obtained. With the current set of markers the centromeric and telomeric boundaries could not be defined (see below).

\section{Discussion}

In both pedigrees the mode of inheritance is autosomal dominant. The clinical features consist of cerebellar symptoms, loss of vision, and both upper and lower motor neuron signs. As commonly found in ADCA I and ADCA II, ${ }^{215}$ anticipation is present. In the oldest generation the disease has a late onset (after 40 years). There is an intermediate age of onset (between 20 and 40 years) and an early onset (younger than 10 years). Young onset is correlated with disease severity and progression. The findings of neuropathological investigation confirm this relation; most extensive changes and degeneration are encountered in patients with juvenile onset. A detailed description of the neuropathological features will be part of a separate article. The families contain too little information to draw firm conclusions on the effect of parental sex on anticipation. Previous findings suggest that anticipation in ADCA II occurs nearly exclusively in the offspring of affected fathers. ${ }^{2}$ However, in one case of early onset (2-III,2; seven years of age) the transmitting parent was the mother.

The pairwise lod scores obtained with chromosome 3p12-p21.1 markers in family 1 exceed $3 \cdot 0$, thus confirming SCA 7 as the genetic locus for ADCA II. Family 2, investigated with the identical set of markers, contained too limited information to disclose genetic linkage (results not shown). However, all genetic data are compatible with linkage to SCA7. The two families do not share a common haplotype of these markers.

The three papers reporting linkage to SCA7 
each delineate the candidate region to a $30-33 \mathrm{cM}$ interval. The telomeric and centromeric boundary defining recombinations occur respectively with D3S1300 and D3S1276, ${ }^{9}$ D3S1289 and D3S1217,8 and D3S1547 and D3S $1274 . .^{10}$ Combination of the various maps yields a confined candidate region between D3S1300 and D3S1217, which amounts to $13.4 \mathrm{cM}$. For family 1 , no recombinations occur within this region. Both the telomeric and centromeric boundaries of family 1 are not properly defined with the currently investigated markers. A telomeric recombination (D3S1234) was found just outside the candidate region in an apparently unaffected member (1-III,16 aged 38 years). At the opposite end of the candidate region, inability to reconstruct the haplotype of the members from the first generation for D3S1217 hinders confinement of the genetic interval. Obligate recombinations with markers outside this interval will establish the true borders for this kindred. However, as it will not contribute to further confinement of the candidate region of $\mathrm{ADCA}$ II, we refrained from investigating such markers. The apparent recombination with $\mathrm{D} 3 \mathrm{~S} 1287$ in patient 1-II,3 must have either arisen from a double recombination event or repeat instability. The first, a recombination between D3S1287 and the informative markers on either side $(3 \mathrm{cM}$ and $8 \mathrm{cM}$ away from D3S1287), has an a priori change of 0.0024 if both recombinations are taken to be independent events. Alternatively, an allele of patient $1-\mathrm{II}, 3$ at D3S1287 may have been subject to microsatellite instability, which has been reported to occur in 1 out of 1000 meioses. ${ }^{16}$

The absence of genetic heterogeneity contrasts with the many loci identified for ADCA I and suggests that a single gene is involved in ADCA with the associated feature of pigmentary retinal degeneration. The resemblance of clinical characteristics and additional features such as anticipation, especially in the offspring of affected fathers, argue that the mutation of ADCA II, as in ADCA I, consists of an expanded CAG repeat. In this respect, the age of onset related presentation in the families currently studied is interesting, as a similar phenomenon has been described in another trinucleotide repeat expansion disorder, Machado-Joseph disease. ${ }^{17} 18$ The pathophysiological mechanisms of CAG repeat expansion have not yet been elucidated; current hypotheses pivot on detrimental effects of polyglutamine stretches. ${ }^{19}$ The characteristic pigmentary macular degeneration of ADCA II might be due to particular expression in the retina. Identification of the ADCA II gene will be facilitated if these considerations are taken into account - for example, by screening P1 or YAC contigs of the candidate region for retina expressed sequences containing CAG repeats.

This study was supported in part by grants from the Schuhmacher-Kramer Foundation and the Prinses Beatrix Fonds. GJJ and JWW have contributed equally to this study.

1 Harding AE. The clinical features and classification of the late onset autosomal dominant cerebellar ataxias. Brain late onset autos

2 Enevoldson TP, Sanders MD, Harding AE. Autosomal dominant cerebellar ataxia with pigmentary macular dystrophy: a clinical and genetic study of eight families. Brain 1994;117:445-60.

3 Rosenberg RN. Autosomal dominant cerebellar phenotypes: the genotype has settled the issue. Neurology 1995; 45:1-5.

4 Stevanin G, LeGuern E, Ravise N, et al. A third locus for autosomal dominant cerebellar ataxia type 1 maps to chromosome 14q24.3-qter: evidence for the existence of a fourth locus. Am F Hum Genet 1994;54:11-20.

5 Ranum LPW, Schut LJ, Lundgren JK, Orr HT, Livingston DM. Spinocerebellar ataxia type 5 in a family descended from the grandparents of President Lincoln maps to chromosome 11. Nature Genet 1994;8:280-4.

6 Gouw LG, Digre KB, Harris CP, Haines JH, Ptacek LJ. Autosomal dominant cerebellar ataxia with retinal degenAutosomal dominant cerebellar ataxia with retinal degeneration: clinical, neuropathologic, and genetic

7 Benomar A, Le Guern E, Dürr A, et al. Autosomal-dominant cerebellar ataxia with retinal degeneration (ADCA type II) is genetically different from ADCA type I. Ann Neurol 1994;35:439-44.

8 Gouw LG, Kaplan CD, Haines JH, et al. Retinal degeneration characterizes a spinocerebellar ataxia mapping to chromosome 3p. Nat Genet 1995;10:89-93.

9 Benomar A, Krols L, Stevanin G, et al. The gene for autosomal dominant cerebellar ataxia with pigmentary macula dystrophy maps to chromosome 3p12-p21.1. Nat Genet 1995;10:84-8.

10 Holmberg M, Johansson J, Forsgren L, Heijbel J, Sandgren $O$, Holmgren $G$. Localization of autosomal dominant cerebellar ataxia associated with retinal degeneration and anticipation to chromosome 3p12-p21.1. Hum Mol Genet anticipation to chro.

11 de Jong PTVM, de Jong JGY, de Jong-ten Doeschate JMM, Delleman JW. Olivopontocerebellar atrophy with visual disturbances. Ophthalmology 1980;87:793-804

12 Toda $T$, Segawa $M$, Nomura $Y$, et al. Localization of a gene for Fukuyama type congenital muscular dystrophy to chromosome 9q31-33. Nat Genet 1993;5:283-6.

13 Schäffer AA, Gupta SK, Shriram K, Cottingham RW. Avoiding recomputation in linkage analysis. Hum Heredity 1994;44:225-37.

14 Lathrop GM, Lalouel JM, Julier C, Ott J. Strategies for multilocus linkage analysis in humans. Proc Natl Acad Sci USA 1984;81:3443-6.

15 Haines JL, Schut LJ, Weitkamp LR. Spinocerebellar ataxia in a large kindred: age at onset, reproduction, and genetic linkage studies. Neurology 1984;34:1542-8.

16 Weissenbach J, Gyapay G, Dib C, et al. A second-generation linkage map of the human genome. Nature 1992; 359:794-801.

17 Coutinho P, Andrade C. Autosomal dominant system degeneration in Portuguese families of the Azores Islands: a new genetic disorder involving cerebellar, pyramidal, extrapyramidal and spinal cord motor functions. Neurology 1978;28:703-9.

18 Kawaguchi $Y$, Okamoto T, Taniwaki $M$, et al. CAG expansions in a novel gene for Machado-Joseph disease at chromosome 14q32.1. Nat Genet 1994;8:221-8.

$19 \mathrm{Cha}$ JH, Dure LS. Trinucleotide repeats in neurologic diseases: an hypothesis concerning the pathogenesis of Huntington's disease, Kennedy's disease, and spinocerebellar ataxia type I. Life Sci 1994;54:1459-64. 